\title{
Integrin as a Molecular Target for Anti-cancer Approaches in Lung Cancer
}

\author{
NITHIKOON AKSORN ${ }^{1}$ and PITHI CHANVORACHOTE ${ }^{2,3}$ \\ ${ }^{1}$ Department of Clinical Pathology, Faculty of Medicine Vajira Hospital, \\ Navamindradhiraj University, Bangkok, Thailand; \\ ${ }^{2}$ Department of Pharmacology and Physiology, Faculty of Pharmaceutical Sciences, \\ Chulalongkorn University, Bangkok, Thailand; \\ ${ }^{3}$ Cell-based Drug and Health Product Development Research Unit, \\ Faculty of Pharmaceutical Sciences, Chulalongkorn University, Bangkok, Thailand
}

\begin{abstract}
Integrins are cell-matrix adhesion molecules providing both mechanical engagement of cell to extracellular matrix, and generation of cellular signals that are implicated in cancer malignancies. The concept that integrins play important roles in cell survival, proliferation, motility, differentiation, and ensuring appropriate cell localization, leads to the hypothesis that inhibition of certain integrins would benefit cancer therapy. In lung cancer, integrins $\alpha v, \alpha 5, \beta 1, \beta 3$, and $\beta 5$ have been shown to augment survival and metastatic potential of cancer cells. This review presents data suggesting integrins as molecular targets for anti-cancer approaches, and the mechanisms through which integrins confer resistance of lung cancer to chemotherapeutics and metastasis. The better understanding of these key molecules may benefit the discovery of anti-cancer drugs and strategies.
\end{abstract}

Lung cancer is, by far, one of the most common human cancers causing nearly 1 in 5 cancer-related mortalities worldwide. Its incidence and mortality have been continuously growing since the 1930s. According to the International Agency for Research on Cancer, more than 1.8 million people were diagnosed and over 1.5 million people died from lung cancer, worldwide (1). Generally, lung cancer can be classified as non-small cell lung

This article is freely accessible online.

Correspondence to: Pithi Chanvorachote, Department of Pharmacology and Physiology, Faculty of Pharmaceutical Sciences, Chulalongkorn University, Patumwan, 10330 Bangkok, Thailand. Tel: +662 2188344, e-mail: pithi.c@chula.ac.th,pithi_chan@yahoo.com

Key Words: Integrin, target therapy, anti-cancer drug, lung cancer, drug discovery, review. cancer (NSCLC) and small cell lung cancer (SCLC). Accounting for approximately $80-85 \%$ of all lung cancer cases, NSCLC can be further categorized into adenocarcinoma, squamous cell carcinoma, and large cell carcinoma, which differ with regard to treatment strategy and clinical outcome (2). Regarding their prognosis, there are differences in terms of the rate of 5-year survival; SCLC has an overall (all stages combined) 5-year survival rate about $6 \%$ and NSCLC approximately $18 \%$. Importantly, the stage of lung cancer referring to their dissemination is critical for the prognosis. Early-stage NSCLC, with no evidence of cancer metastasis, has a 5-year survival rate of nearly $50 \%$, while late stage metastatic NSCLC has only 1$2 \%$. Together with other evidence, it is well known that the key factor determining the success of lung cancer management is whether the cancer has metastasized or not. While the primary tumor of lung can be completely managed by surgery, the disseminated cancers at late stages are very difficult to be eliminated. Chemotherapies and other drugs, like targeted therapies, are being continuously developed for the treatment of metastatic lung cancer. Despite the variety offered, most of them fail to completely cure cancer. At present, lung cancer is accepted as one of the most aggressive malignancies, with only 10-15\% 5-year survival (3). Moreover, poor survival of lung cancer patients is largely contributed to patients being diagnosed at a metastatic stage and more than half of patients having distant metastases. The understanding of the fundamental basis of key regulatory mediators of cancer metastasis could be useful for the discovery of novel therapeutic targets that will provide more precise and effective therapeutic approaches.

\section{Integrins}

Integrins are transmembrane proteins functioning as cell surface protein receptors that control cell adhesion to 
extracellular matrix (ECM) and provide mechanical adhesion by linking cytoskeletal actins to ECM molecules. Besides, integrins function biochemically by sensing the appropriate cell embeds or contact to their environment. The integrinECM component interactions initiate signal transduction pathways regulating several fundamental activities of the cells, including cell proliferation, differentiation, and movement. In addition, the firm engagement of integrin to ECM components ensures the correct location and appropriate cell adhesion resulting in the generation of cell survival signals (4).

In summary, the two main functions of integrins are mechanical attachment of the cell to the ECM and initiation of signal transduction pathways. Basically, if the cell to ECM adhesion is appropriate and firm, ligand binding to integrins will transmit fundamental signals of cell survival. These signals are of importance for metastasis of cancer cells, as the lack of cellECM adhesion causes the withdrawal of these survival signals resulting in detachment-induced apoptosis termed "anoikis". Escaping from anoikis has been long recognized as one key mechanism rendering success in metastasis, and certain types of integrins were demonstrated to help cancer cells resist anoikis (5). The integrin family consists of alpha $(\alpha)$ and beta $(\beta)$ subtypes. These alpha and beta subtypes of integrins form heterodimers at cell membrane. So far, at least 24 distinct integrin heterodimers have been identified in humans as a consequence of paring interaction of $18 \alpha$ - and $8 \beta$-subunits. The binding of integrins to their ligands in ECM is through the recognition of the specific arginine-glycine-aspartic acid (RGD) sequence. Later on, EILDV and REDV sequences have also been reported to mediate such interactions (6). Evidence has suggested that each specific heterodimer provides a unique pattern of cell signaling, as specific pair of integrins preferentially binds to different ligands of ECM. For instance, the $\alpha 4 \beta 1$ integrins bind to EILDV and REDV sequences in fibronectin, while a5 $\beta 1$ integrins recognize the RGD sequence (7). The integrin-ligand engagement senses extracellular the extracellular environment to trigger cellular responses, including cell survival, division, migration, and invasion. Like adherent normal cells, lung cancer and other solid tumor cells require the firm engagement of integrins to ECM component in providing fundamental survival signals, and in the detached cells lacking such integrin-mediated signals, cancer cells will undergo anoikis

Integrin signaling can be modulated by cell stress as well as in response to the signals from the cellular microenvironment. Nitric oxide (NO), an important mediator of cellular behaviors, was found to increase integrin $\alpha \mathrm{v}$ and $\beta 1$ in NSCLC cells via protein kinase $\mathrm{G}(\mathrm{PKG}) /$ protein kinase $\mathrm{B}$ (Akt)-dependent mechanism (8). In response to chemotherapeutic drug, we have demonstrated that treatment of NSCLC cells with sub-toxic concentrations of cisplatin exhibited an alteration of integrin signaling that enhances filopodia formation of the cells and induces cell migration. In such a case, cisplatin could increase the cellular levels of integrin $\alpha 4$, $\alpha v, \beta 1$, and $\beta 5$, while integrins $\alpha 5$ and $\beta 3$ were not altered. Consistent with previous reports, integrin $\alpha 4, \alpha v, \beta 1$, and $\beta 5$ were shown to increase motility of cancer cells (9).

\section{Basic Structure of Alpha and Beta Integrins}

Integrins consist $18 \alpha$ - and $8 \beta$-subunits that pair and incorporate into 24 different heterodimers. The integrin dimers bind to ECM components such as collagen, fibronectin, fibrinogen, laminin, and vitronectin as their ligands. The integrins have a large extracellular domain with several subdomains of $\alpha$ and $\beta$ subunits that interact with ECM ligands. Also, the protein contains a transmembrane domain and a short cytoplasmic domain which interacts with the cytoskeleton and plays central roles in signal transduction (10).

$\alpha$ subunit consists of an extracellular domain of sevenbladed $\beta$-propeller head domain, a thigh domain and two calf domains (calf 1 and calf 2 ), and $\alpha I$-domain containing around 200 amino-acids which is inserted between the $\beta$-propeller blade 2 and 3 . The $\alpha$ I-domain contains a metal ion-dependent adhesion site (MIDAS) involved in ligand binding. On the other hand, the $\beta$ subunit comprises of a plexin-sempahorinintegrin (PSI) domain, a hybrid domain, an I-like domain ( $\beta \mathrm{I})$ which is inserted in the hybrid domain and is homologous to $\alpha I$-domain of the $\alpha$ subunit, 4 epidermal growth factor (EGF) repeats (EGF1-4), and $\beta$ tail domain (Figure 1A) (11).

During the cell adherence to ECM, activation of integrin is controlled by bidirectional signals including outside-in signal where extracellular ligand interaction activates integrin receptor by separating the integrin cytoplasmic domain triggering the intracellular signaling molecules and "insideout" signal where signals from inside the cell activate the integrin for binding to the extracellular ligands (10). In detail, the bent conformation (resting stage of integrin) of integrin has low affinity to the ligand and the transmembrane domains are close with cytoplasmic domains by the salt bridge. Insideout signaling involves the intracellular activators talin and kindlin that bind to the $\beta$-subunit leading to change of integrin conformation to the extend conformation (active conformation) with high ligand binding affinity.

For outside-in signaling, the integrins bind to the various extracellular ligands such as fibronectin, collagen, and laminin leading to the conformational change that induces focal adhesion complex formation at the integrin cytoplasmic tail that connects integrin to cytoskeletal proteins and regulates several cellular signals that control cell adhesion, survival, proliferation, differentiation, and motility (Figure 1B) (10).

\section{Integrin and Cancers}

It has been hypothesized that integrins could control several aggressive behaviors of cancer cells. According to the fact that cancer cells require strong survival as well as proliferative 
A

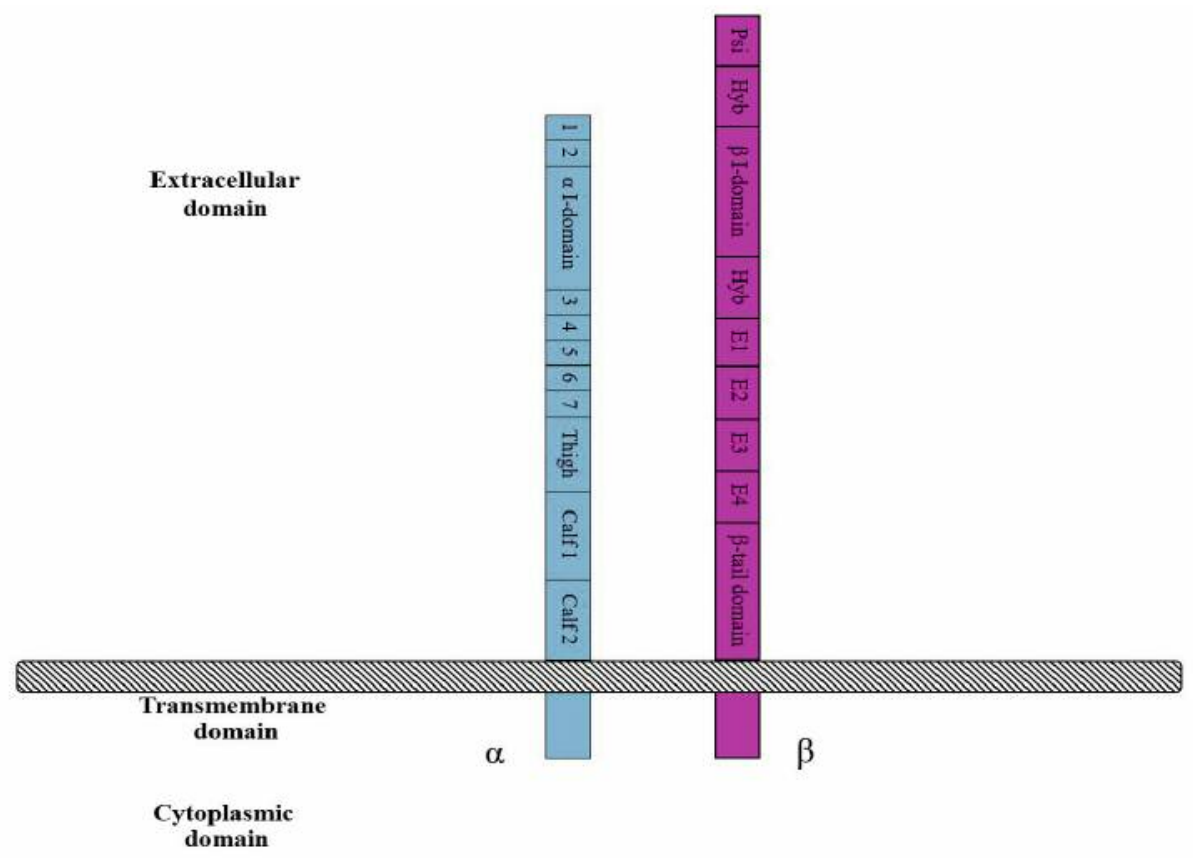

B

\section{'Outside-in' signaling}

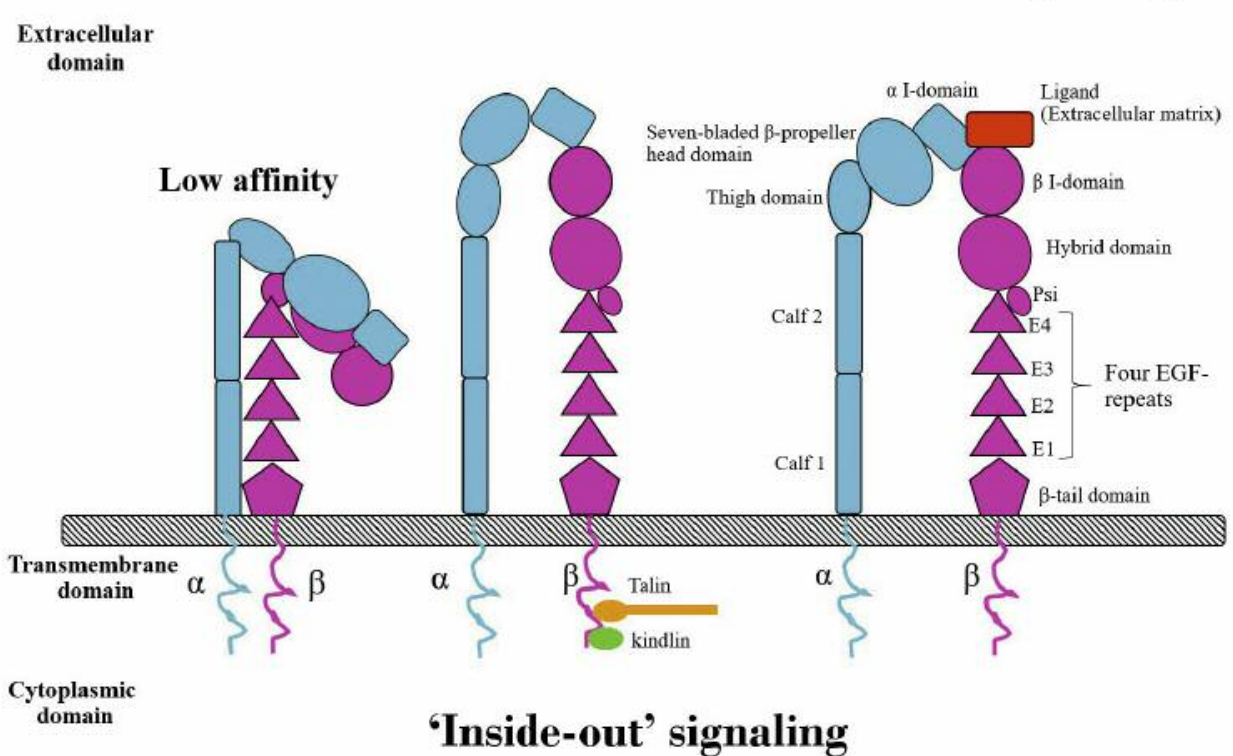

Figure 1. Integrin structure. (A) Domain structure of $\alpha$ - and $\beta$-subunits; (B) Schematic illustration of "Outside-in" and "Inside-out" integrin signaling.

signals for which integrins are known to be very essential, these unique protein receptors have garnered increase attention as they may be promising targets for anti-cancer approaches. Regarding cell signaling and protein expression, the engagement of integrins and their ECM ligands is critical for gene expression and a variety of biological processes. The extracellular and intracellular signaling of integrin is important for the regulation of cell functions such as adhesion, migration, growth, differentiation, survival, and apoptosis and plays a crucial role in pathological processes which lead to migration and tumor progression (12). Regarding cell migration and invasion, integrins are a major family of migration-promoting receptors that act as the feet of a migrating cell by supporting adhesion to the extracellular matrix through the link with intracellular actin filaments. Integrin $\beta 1, \beta 3, \alpha v$ and $\alpha 5$ play a major role in cancer 
metastasis and survival of cancer patients. A variety of integrins can be found in many cancers such melanoma (13), breast carcinoma (14), prostate (15), pancreatic (16) and lung cancer (17). Moreover, several receptor tyrosine kinases that enhance survival and growth of cancer cells such vascular endothelial growth factor receptor 2 (VEGFR2), epidermal growth factor receptor (EGFR) and platelet-derived growth factor receptor (PDGFR) were shown to be linked with integrin signaling (18).

Integrins are well-known mediators of survival cell signals including the phosphatidylinositol 3-kinase (PI3-K)/ Protein kinase B (Akt) pathway, the Mitogen-Activated Protein Kinase (MAPK) /Extracellular Regulated Kinase (Erk) pathway, Stress-Activated MAP Kinases (SAPKs), and c-Jun Nterminal kinase (JNK) (19). It is also known that integrins are non-kinase receptors, so the transduction of mentioned signals requires kinase partners. Integrin-mediated intracellular signaling is previously shown to depend on the recruitment and function of focal adhesion kinase (FAK) (20). FAK, a non-receptor protein tyrosine kinase that is localized in focal adhesions, is a ubiquitously expressed $125-\mathrm{kDa}$ cytoplasmic tyrosine kinase that regulates migration and proliferation. FAK can be activated by integrin, G-protein-coupled receptors or growth factors-linked stimuli (20). In addition, integrinregulated FAK-Src signaling allows downstream activation of multiple intracellular signaling pathways, including the PI3K/Akt and MAPK/Erk pathways. Akt is a serine/threoninespecific protein kinase, which is activated by PI3K. Akt is a key regulator of signaling and induction of metastasis (21). Besides, integrin could interact with other adapter proteins and kinases, including p130CAS, Grb 2, and paxillin, resulting in cell survival and movement (22). Integrin engagement to ECM molecule was shown to be directly mediated by Akt activation via $\mathrm{PI} 3 \mathrm{~K}$ signaling through the direct recruitment of PI3K to integrin subunit (23). The activation of MAPK/Erk pathways is related to promotion of tumor progression, cell survival and proliferation (24). JNK induces phosphorylation of paxillin, a component of focal adhesions. The integrin-mediated activation of the FAK-JNK pathway is necessary for controlling cell cycle (25). FAK acts as a phosphorylationregulated scaffold to recruit Src to focal adhesions. Src phosphorylates, the adaptor protein p130 CRK-associated substrate (p130CAS) and paxillin, the Crk-DOCK180 complex, and thereby results in the activation of Rac which is involved in cell migration (12). This signal transduction pathway leads to the regulation of cancer cell migration and cell invasion (26). The activation of FAK principally initiated by integrin engagement to ECMs and also by growth factor receptors enables regulation of cell survival, proliferation, migration, invasion, progression and metastasis in relation to cancer development. Subsequently, the autophosphorylation of FAK on Tyr397 mediates high affinity binding of the Src homology 2 (SH2) domain of Src kinase (27). FAK/Src complex empowers tyrosine phosphorylation cascades to modulate versatile signal pathways and improve cell motility. For example, FAK modulates endophilin A2 phosphorylation by Src or PI3K-AKT signaling in cancer stem cells. In endothelial cells, vascular endothelial growth factor-A (VEGFA)/VEGF or angiopoietin-1 signaling regulates FAK-mediated $\mathrm{PI} 3 \mathrm{~K} / \mathrm{AKT}$ activation to promote migration, sprouting, and angiogenesis. FAK also regulates the expression of growth factors or cytokines in tumor-associated macrophages to facilitate cancer progression. In response to lysyl oxidase-like 2 (LOXL2) which is important for stimulation tumorigenesis, FAK affects the $\alpha$-smooth muscle actin ( $\alpha$-SMA) expression and AKT signaling to control cell invasion, metastasis, angiogenesis, anti-apoptosis, and proliferation of cancerassociated fibroblasts (28). Alternatively, evidences have pointed out that $\mathrm{Src}$ can also interacts with the cytoplasmic domain of integrin at $\beta$ subunits and generates survival signal by activating FAK (29).

\section{Integrins and Survival of Lung Cancer}

Being one of the hallmarks of cancer, the spread of the deadly cells from one site to others does not only reflect the progression of the disease but also contributes to the poor prognosis as well. The metastatic behavior of lung cancer cells is enhanced when the metastatic cascade is activated (26). Subsequently, epithelial cells of the primary tumor undergo Epithelial-Mesenchymal Transition (EMT). Afterwards, they invade through ECM and stromal cell layers by the facilitation of proteinases. The tumor cells intravasate into the blood vessels of the tumor or nearby. Thereafter, they are carried through the vasculature and arrested at distant sites. The cells then extravasate into the distant tissues. The extravasated tumor cells can survive at the metastatic sites and form metastatic colonization, where they may grow as a secondary tumor. Based on the above, the therapeutic approach can have three targets, first the induction of apoptosis in primary tumor, second induction of apoptosis in the metastasis tumor and third, inhibition of various steps of metastasis. Finally, the therapeutic approach should be specific for cancer without causing damage to non-cancer cells and also targeting aggressive cancer cells. When considering the three critical factors, integrins may play a role in all of them. There is evidence that in lung cancer integrins play an important role in metastasis. A recent study has demonstrated that in NSCLC, integrin $\alpha 11$ and $\beta 1$ can augment metastasis potential and increase tumorigenicity (30). Furthermore, integrin $\alpha 11$ was shown to up-regulate IGF2 expression in fibroblasts and thereby increase ability of NSCLC cells to form new tumors (31). Integrin $\alpha 5 \beta 1$ was shown to facilitate cancer cell invasion and enhance EGFR signaling (32). In association with EGFR signaling, integrin $\beta 1$ was shown to mediate erlotinib resistance in lung cancer by activating Src/Akt-driven 
bypass signaling (33). In detail, erlotinib is a selective kinase inhibitor that exhibits good efficacy in NSCLC having EGFRactivating mutations. The development of erlotinib resistance occurs via the activation of the Src/Akt signaling through the activity of integrin $\beta 1$ (33). As augmentation of Akt related survival is linked with resistance to chemotherapeutic and targeted therapy, the increase of integrin $\beta 1$-associated lung cancer drug resistance was frequently reported. In NSCLC, the increase in the level of integrin $\beta 1$ is shown to associate with resistance to Gefitinib (34). Likewise, integrin $\alpha 2 \beta 1$ is shown to cause resistance to doxorubicin in lung cancer (35). Kaplan-Meyer survival analysis shows that integrin $\alpha v \beta 6$ is related to poor prognosis of NSCLC patients (36). The mechanistic explaining the prognostic value of integrin $\alpha \mathrm{v} \beta 6$ on NSCLC involves its ability to enhance TGF $\beta$ activity in cancer cells (37).

\section{Integrins and Other Cancers}

Integrins have been shown to be a dominant factor in enhancing cancer aggressiveness. High expression of integrin $\alpha v$ and $\beta 3$ has been shown to closely associate with bone metastasis and tissue remodeling in prostate cancer (15). Besides, integrin $\alpha \mathrm{v}$ and $\beta 3$ overexpression in prostate cancer tightly relates to angiogenesis and tumor metastasis potentials (38). Moreover, integrin $\alpha \mathrm{v}$ and $\beta 3$ facilitates bone remodeling that results in bone metastasis by mediating adhesion and migration via vitronectin (39). In esophageal carcinomas, the integrin $\alpha 6$ has been shown to link with tumor invasion (40). For pancreatic cancer, integrins $\alpha 2 \beta 1$, $\alpha 5 \beta 1$ and $\alpha v \beta 5$ have been shown to mediate cancer cell adhesion to the ECM components fibronectin, laminin, collagen, and vitronectin, respectively (41). These integrin engagements are involved in cell proliferation and essential for cancer invasion.

\section{Integrins in Anticancer Therapy}

According to the fact that integrins are key molecules contributing to cancer progression and metastasis, attempts are being made in order to develop integrin-targeting anticancer drugs. Angiogenesis is an essential factor for tumor progression and metastasis. Integrins play a key role in the regulation of the process of tumor angiogenesis which consists of basement membrane degradation, endothelial cell migration, proliferation, and stabilization (42). Integrins $\alpha v \beta 3$ and $\alpha v \beta 5$, which are not usually expressed in epithelial cells, have been found to be important regulators of the process of tumor angiogenesis, (43). Inhibition of the $\alpha v \beta 3$ and $\alpha v \beta 5$ binding with ECM ligands has been targeted for blocking endothelial cell-mediated angiogenesis and tumor metastasis. Therefore, integrin blocking agents have become attractive mediators for therapeutic targeted therapy.
Currently, several integrin antagonists are developed for anticancer therapy. Cilengitide, an arginine-glycine-aspartic acid (RGD) pentapeptide of $\alpha v \beta 3$ and $\alpha v \beta 5$ integrins inhibitor, is progressed in phase II and III clinical trials in recurrent glioblastoma (44). Volociximab, a chimeric human IgG4 antibody inhibitor of $\alpha 5 \beta 1$, is evaluated in phase II clinical trials in metastatic melanoma, renal cell carcinoma and NSCLC (45).

\section{Potential Compounds Targeting Integrins for Anti-cancer Approaches}

Since integrins have been shown to be implicated in cancer progression and metastasis, several active compounds targeting the integrin molecules are under investigation for efficacy, as well as safety in pre-clinical and clinical trials. Excluding specific antibodies against integrins, several natural product compounds have exhibited a desirable effect in modulating integrin signaling. Certain integrins have been shown to associate with the aggressive phenotypes of cancer and suppression of such integrins would benefit chemoprevention and cancer therapy.

Ouabain, a biologically active compound and plant-derived cardioactive glycoside from the seeds of Strophanthus gratus also recognized as a human hormone, has been shown to affect integrin expression in human lung cancer cells. Treatment of the lung cancer cells with non-toxic concentrations of ouabain resulted in dramatic decrease of the cellular levels of integrin $\alpha 4, \alpha 5, \alpha v, \beta 3$ and $\beta 4$, with no significant effect on integrin $\beta_{1}$ and $\beta_{4}$. Such integrin switch caused by ouabain suppressed the migratory activity of lung cancer cells (46). Likewise, we previously found that $\alpha$-Lipoic acid sensitized lung cancer cells to chemotherapeutic agents and anoikis by decreasing the levels of integrin $\beta 1$ and $\beta 3$. The underlying mechanism of modulation of the expression of such integrins involves the induction of intracellular superoxide anion $\left(\mathrm{O}_{2}{ }^{-}\right)$and hydrogen peroxide $\left(\mathrm{H}_{2} \mathrm{O}_{2}\right)$ (47). Lectin from Morus alba Leaf has been shown to enhance anoikis response in breast cancer cells via a mechanism involving the disruption of fibronectin-integrinFAK signaling. Treatment of the MCF-7 cancer cells with this lectin resulted in the depletion of integrin levels followed by the decrease of active FAK and active Ras. As a consequence, the lack of integrin-mediated cell survival signals sensitized the cell to anoikis (48).

Curcumin, a bioactive compound from the rhizome Curcuma longa, has been demonstrated to have a promising anti-cancer activity (49). In terms of integrins, curcumin is demonstrated to inhibit the function of $\alpha 6 \beta 4$ in mediating breast cancer cell motility. The disruption of integrin function caused a significant reduction in the activation of Akt and thereby decreased the levels of the migration promoting factor ENPP2 (50). In addition, curcumin is shown to be down-regulate integrin $\alpha v \beta 3$ that could benefit to the treatment of erlotinib resistant colon cancer cells (51). 
Phloretin, a flavonoid bioactive compound found in fruits such apples and strawberries, has several biological functions such as anticancer activity (52), antibacterial activity (53) and prevention of cardiovascular disease (54). $\alpha v \beta 3$ integrin has been shown to be overexpressed in osteoclasts and to play important roles in osteoclast migration and activation. Phloretin has been shown to suppresses paxillin induction in receptor activator of nuclear factor $x \mathrm{~B}$ ligand (RANKL)activated osteoclasts and in ovariectomized (OVX) epiphyseal bone tissues, to reduce RANKL-stimulated resorptive activity in osteoclasts, promote osteoclast apoptosis and to disrupt $\alpha v \beta 3$ integrin-c-Src-mediated actin cytoskeletal reorganization responsible for bone resorption (55).

Gambogic acid, the major active ingredient of gamboge which is extracted from the resin of Garciania hanburyi, inhibits tumor progression in several cancers including breast cancer (56), gastric cancer (57) and lung cancer (58). Gambogic acid suppresses the epithelial-to-mesenchymal transition (EMT) and nuclear factor-kappa B (NF-kappa B) signaling pathway (59). Gambogic acid inhibits activation of vascular endothelial growth factor receptor 2 (VEGFR2) and downstream protein kinases including c-Src, FAK and AKT (60). Gamboge acid could be developed as an anticancer agent.

\section{Conflicts of Interest}

The Authors have no conflicts of interest to declare.

\section{Authors' Contributions}

Conceptualization: P.C. and N.A.; Writing-original draft preparation: N.A. and P.C.; Writing - review and editing: P.C.

\section{Acknowledgements}

This work was supported by the Grant for International Research Integration: Chula Research Scholar, Ratchadaphiseksomphot Endowment Fund. The Authors would like to thank Cell-based Drug and Health Products Development Research Unit, Chulalongkorn University.

\section{References}

1 Ervik M LF, Ferlay J, Mery L, Soerjomataram I and Bray F: Cancer today. International Agency for Research on Cancer, Lyon, France, 2016.

2 Herbst RS, Heymach JV and Lippman SM: Lung cancer. N Engl J Med 359: 1367-1380, 2008. PMID: 18815398, DOI: 10.1056/NEJMra0802714.

3 Stewart BW and Wild CP: World Cancer Report 2014. International Agency for Research on Cancer. Lyon, France, 2014.

4 Kim YN, Koo KH, Sung JY, Yun UJ and Kim H: Anoikis resistance: an essential prerequisite for tumor metastasis. Int $\mathrm{J}$ Cell Biol 2012: 306879, 2012. PMID: 22505926, DOI:10.1155/2012/306879.
5 Vachon PH: Integrin signaling, cell survival, and anoikis: distinctions, differences, and differentiation. J Signal Transduct 2011: 738137, 2011. PMID: 21785723, DOI: 10.1155/ 2011/738137.

6 Desgrosellier JS and Cheresh DA: Integrins in cancer: biological implications and therapeutic opportunities. Nat Rev Cancer 10: 9-22, 2010. PMID: 20029421, DOI: 10.1038/nrc2748.

7 Plow EF, Haas TA, Zhang L, Loftus J and Smith JW: Ligand binding to integrins. J Biol Chem 275: 21785-21788, 2000. PMID: 10801897, DOI: 10.1074/jbc.R000003200.

8 Saisongkorh V, Maiuthed A and Chanvorachote P: Nitric oxide increases the migratory activity of non-small cell lung cancer cells via AKT-mediated integrin $\alpha v$ and $\beta 1$ upregulation. Cell Oncol (Dordr) 39: 449-462, 2016. PMID: 27376838, DOI: 10.1007/s13402-016-0287-3.

9 Maiuthed A and Chanvorachote P: Cisplatin at sub-toxic levels mediates integrin switch in lung cancer cells. Anticancer research 34: 7111-7117, 2014. PMID: 25503138.

10 Hynes RO: Integrins: bidirectional, allosteric signaling machines. Cell 110: 673-687, 2002. PMID: 12297042, DOI: 10.1016/S0092-8674(02)00971-6.

11 Arnaout MA: Integrin structure: new twists and turns in dynamic cell adhesion. Immunological reviews 186: 125-140, 2002. PMID: 12234368, DOI: 10.1046/j.0019-2805.2001.01368.x-i1.

12 Guo W and Giancotti FG: Integrin signalling during tumour progression. Nat Rev Mol Cell Biol 5: 816-826, 2004. PMID: 15459662, DOI: $10.1038 / \mathrm{nrm} 1490$.

13 Nip J, Shibata H, Loskutoff DJ, Cheresh DA and Brodt P: Human melanoma cells derived from lymphatic metastases use integrin $\alpha v \beta 3$ to adhere to lymph node vitronectin. J Clin Invest 90 : 1406-1413, 1992. PMID: 1383272, DOI: 10.1172/ JCI116007.

14 Takayama S, Ishii S, Ikeda T, Masamura S, Doi M and Kitajima M: The relationship between bone metastasis from human breast cancer and integrin $\alpha v \beta 3$ expression. Anticancer Res 25: 79-83, 2005. PMID: 15816522.

15 McCabe NP, De S, Vasanji A, Brainard J and Byzova TV: Prostate cancer specific integrin $\alpha v \beta 3$ modulates bone metastatic growth and tissue remodeling. Oncogene 26: 6238-6243, 2007. PMID: 17369840, DOI: 10.1038/sj.onc.1210429.

16 Hosotani R, Kawaguchi M, Masui T, Koshiba T, Ida J, Fujimoto $\mathrm{K}$, Wada M, Doi R and Imamura M: Expression of integrin $\alpha v \beta 3$ in pancreatic carcinoma: relation to MMP-2 activation and lymph node metastasis. Pancreas 25: e30-5, 2002. PMID: 12142752, DOI: 10.1097/00006676-200208000-00021.

17 Adachi M, Taki T, Higashiyama M, Kohno N, Inufusa $\mathrm{H}$ and Miyake M: Significance of integrin $\alpha 5$ gene expression as a prognostic factor in node-negative non-small cell lung cancer. Clin Cancer Res 6: 96-101, 2000. PMID: 10656437.

18 Somanath PR, Malinin NL and Byzova TV: Cooperation between integrin $\alpha v \beta 3$ and VEGFR2 in angiogenesis. Angiogenesis 12: 177-185, 2009. PMID: 19267251, DOI: 10.1007/s10456-009-9141-9.

19 Luo DY, Wazir R, Tian Y, Yue X, Wei TQ and Wang KJ: Integrin $\alpha \mathrm{V}$ mediates contractility whereas integrin $\alpha 4$ regulates proliferation of human bladder smooth muscle cells via FAK pathway under physiological stretch. J Urol 190: 1421-1429, 2013. PMID: 23587631, DOI: 10.1016/j.juro.2013.04.027.

20 Mitra SK, Hanson DA and Schlaepfer DD: Focal adhesion kinase: in command and control of cell motility. Nat Rev Mol Cell Biol 6: 56-68, 2005. PMID: 15688067, DOI: 10.1038/ nrm1549. 
21 Gary DS and Mattson MP: Integrin signaling via the PI3-kinaseAkt pathway increases neuronal resistance to glutamate-induced apoptosis. J Neurochem 76: 1485-1496, 2001. PMID: 11238733, DOI: 10.1046/j.1471-4159.2001.00173.x.

22 Schwartz MA and Baron V: Interactions between mitogenic stimuli, or, a thousand and one connections. Curr Opin Cell Biol 11: 197-202, 1999. PMID: 10209147, DOI: 10.1016/S09550674(99)80026-X.

23 Engelman JA: Targeting PI3K signalling in cancer: opportunities, challenges and limitations. Nat Rev Cancer 9: 550-562, 2009. PMID: 19629070, DOI: 10.1038/nrc2664.

24 De Luca A, Maiello MR, D’Alessio A, Pergameno M and Normanno N: The RAS/RAF/MEK/ERK and the PI3K/AKT signalling pathways: role in cancer pathogenesis and implications for therapeutic approaches. Expert Opin Ther Targets 16: S17-27, 2012. PMID: 22443084, DOI: 10.1517/ 14728222.2011.639361.

25 Oktay M, Wary KK, Dans M, Birge RB and Giancotti FG: Integrin-mediated activation of focal adhesion kinase is required for signaling to Jun NH2-terminal kinase and progression through the G1 phase of the cell cycle. J Cell Biol 145: 1461-1469, 1999. PMID: 10385525, DOI: 10.1083/jcb.145.7.1461.

26 Geiger TR and Peeper DS: Metastasis mechanisms. Biochim Biophys Acta 1796: 293-308, 2009. PMID: 19683560, DOI: 10.1016/j.bbcan.2009.07.006.

27 Schaller MD, Hildebrand JD, Shannon JD, Fox JW, Vines RR and Parsons JT: Autophosphorylation of the focal adhesion kinase, pp125FAK, directs SH2-dependent binding of pp60src. Mol Cell Biol 14: 1680-1688, 1994. PMID: 7509446, DOI: 10.1128/MCB.14.3.1680.

28 Tai YL, Chen LC and Shen TL: Emerging roles of focal adhesion kinase in cancer. Biomed Res Int 2015: 690690, 2015 PMID: 25918719, DOI: 10.1155/2015/690690.

29 Mitra SK and Schlaepfer DD: Integrin-regulated FAK-Src signaling in normal and cancer cells. Curr Opin Cell Biol 18: 516-523, 2006. PMID: 16919435, DOI: 10.1016/j.ceb.2006. 08.011

30 Navab R, Strumpf D, To C, Pasko E, Kim KS, Park CJ, Hai J, Liu J, Jonkman J, Barczyk M, Bandarchi B, Wang YH, Venkat K, Ibrahimov E, Pham NA, Ng C, Radulovich N, Zhu CQ Pintilie M, Wang D, Lu A, Jurisica I, Walker GC, Gullberg D and Tsao MS: Integrin $\alpha 11 \beta 1$ regulates cancer stromal stiffness and promotes tumorigenicity and metastasis in non-small cell lung cancer. Oncogene 35: 1899-1908, 2016. PMID: 26148229, DOI: $10.1038 /$ onc .2015 .254 .

31 Zhu CQ, Popova SN, Brown ER, Barsyte-Lovejoy D, Navab R, Shih W, Li M, Lu M, Jurisica I, Penn LZ, Gullberg D and Tsao MS: Integrin $\alpha 11$ regulates IGF2 expression in fibroblasts to enhance tumorigenicity of human non-small-cell lung cancer cells. Proc Natl Acad Sci USA 104: 11754-11759, 2007. PMID: 17600088, DOI: 10.1073/pnas.0703040104.

32 Mierke CT, Frey B, Fellner M, Herrmann M and Fabry B: Integrin $\alpha 5 \beta 1$ facilitates cancer cell invasion through enhanced contractile forces. J Cell Sci 124: 369-383, 2011. PMID: 21224397, DOI: $10.1242 /$ jcs.071985.

33 Kanda R, Kawahara A, Watari K, Murakami Y, Sonoda K, Maeda M, Fujita H, Kage M, Uramoto H, Costa C, Kuwano M and Ono M: Erlotinib resistance in lung cancer cells mediated by integrin $\beta 1 / \mathrm{Src} / \mathrm{Akt}$-driven bypass signaling. Cancer Res 73 :
6243-6253, 2013. PMID: 23872583, DOI: 10.1158/00085472.CAN-12-4502.

$34 \mathrm{Ju} \mathrm{L}$, Zhou C, Li W and Yan L: Integrin beta1 over-expression associates with resistance to tyrosine kinase inhibitor gefitinib in non-small cell lung cancer. J Cell Biochem 111: 1565-1574, 2010. PMID: 21053345, DOI: 10.1002/jcb.22888.

35 Naci D, El Azreq MA, Chetoui N, Lauden L, Sigaux F, Charron D, Al-Daccak R and Aoudjit F: $\alpha 2 \beta 1$ integrin promotes chemoresistance against doxorubicin in cancer cells through extracellular signal-regulated kinase (ERK). J Biol Chem 287: 17065-17076, 2012. PMID: 22457358, DOI: 10.1074/ jbc.M112.349365.

36 Elayadi AN, Samli KN, Prudkin L, Liu YH, Bian A, Xie XJ, Wistuba II, Roth JA, McGuire MJ and Brown KC: A peptide selected by biopanning identifies the integrin $\alpha v \beta 6$ as a prognostic biomarker for nonsmall cell lung cancer. Cancer Res 67: 5889-5895, 2007. PMID: 17575158, DOI: 10.1158/00085472.CAN-07-0245.

37 Sheppard D: Roles of $\alpha \mathrm{v}$ integrins in vascular biology and pulmonary pathology. Curr Opin Cell Biol 16: 552-557, 2004. PMID: 15363806, DOI: 10.1016/j.ceb.2004.06.017.

38 Brooks PC, Montgomery AM, Rosenfeld M, Reisfeld RA, Hu T, Klier $G$ and Cheresh DA: Integrin $\alpha_{\mathrm{v}} \beta_{3}$ antagonists promote tumor regression by inducing apoptosis of angiogenic blood vessels. Cell 79: 1157-1164, 1994. PMID: 7528107, DOI: 10.1016/0092-8674(94)90007-8.

39 Ross FP, Chappel J, Alvarez JI, Sander D, Butler WT, FarachCarson MC, Mintz KA, Robey PG, Teitelbaum SL and Cheresh DA: Interactions between the bone matrix proteins osteopontin and bone sialoprotein and the osteoclast integrin $\alpha \mathrm{v} \beta 3$ potentiate bone resorption. J Biol Chem 268: 9901-9907, 1993. PMID: 8486670.

40 Tanaka Y, Mimori K, Shiraishi T, Ohkura Y, Takubo K, Mafune $\mathrm{K}$, Barnard GF and Mori M: alpha6 integrin expression in esophageal carcinoma. Int J Oncol 16: 725-729, 2000. PMID: 10717240, DOI: 10.3892/ijo.16.4.725.

41 Grzesiak JJ and Bouvet M: Determination of the ligand-binding specificities of the $\alpha 2 \beta 1$ and $\alpha 1 \beta 1$ integrins in a novel 3dimensional in vitro model of pancreatic cancer. Pancreas 34 : 220-228, 2007. PMID: 17312461, DOI: 10.1097/01.mpa.00002 50129.64650.f6

42 Foubert $\mathrm{P}$ and Varner JA: Integrins in tumor angiogenesis and lymphangiogenesis. Methods Mol Biol 757: 471-486, 2012. PMID: 21909928, DOI: 10.1007/978-1-61779-166-6_27.

43 Erdreich-Epstein A, Shimada H, Groshen S, Liu M, Metelitsa LS, Kim KS, Stins MF, Seeger RC and Durden DL: Integrins $\alpha v \beta 3$ and $\alpha v \beta 5$ are expressed by endothelium of high-risk neuroblastoma and their inhibition is associated with increased endogenous ceramide. Cancer Res 60: 712-721, 2000. PMID: 10676658 .

44 Mas-Moruno C, Rechenmacher F and Kessler H: Cilengitide: the first anti-angiogenic small molecule drug candidate design, synthesis and clinical evaluation. Anticancer Agents Med Chem 10: 753-768, 2010. PMID: 21269250, DOI: 10.2174/187 152010794728639

45 Kuwada SK: Drug evaluation: Volociximab, an angiogenesisinhibiting chimeric monoclonal antibody. Curr Opin Mol Ther 9: 92-98, 2007. PMID: 17330407.

46 Ninsontia $\mathrm{C}$ and Chanvorachote P: Ouabain mediates integrin switch in human lung cancer cells. Anticancer research 34: 54955502, 2014. PMID: 25275046. 
47 Puchsaka P, Chaotham C and Chanvorachote P: $\alpha$-Lipoic acid sensitizes lung cancer cells to chemotherapeutic agents and anoikis via integrin $\beta 1 / \beta 3$ downregulation. Int $\mathrm{J}$ Oncol 49: 1445 1456, 2016. PMID: 27431988, DOI: 10.3892/ijo.2016.3624.

48 Saranya J, Shilpa G, Raghu KG and Priya S: Morus alba Leaf Lectin (MLL) Sensitizes MCF-7 Cells to Anoikis by Inhibiting Fibronectin Mediated Integrin-FAK Signaling through Ras and Activation of P38 MAPK. Front Pharmacol 8: 34, 2017. PMID: 28223935, DOI: 10.3389/fphar.2017.00034.

49 Wilken R, Veena MS, Wang MB and Srivatsan ES: Curcumin: A review of anti-cancer properties and therapeutic activity in head and neck squamous cell carcinoma. Mol Cancer 10: 12, 2011. PMID: 21299897, DOI: 10.1186/1476-4598-10-12.

50 Kim HI, Huang H, Cheepala S, Huang S and Chung J: Curcumin inhibition of integrin ( $\alpha 6 \beta 4)$-dependent breast cancer cell motility and invasion. Cancer Prev Res (Phila) 1: 385-391, 2008. PMID: 19138983, DOI: 10.1158/1940-6207.CAPR-08-0087.

51 Javadi S, Rostamizadeh K, Hejazi J, Parsa M and Fathi M: Curcumin mediated down-regulation of $\alpha_{\mathrm{v}} \beta_{3}$ integrin and upregulation of pyruvate dehydrogenase kinase 4 (PDK4) in Erlotinib resistant SW480 colon cancer cells. Phytother Res 32: 355-364, 2018. PMID: 29168312, DOI: 10.1002/ptr.5984.

52 Yang CS, Landau JM, Huang MT and Newmark HL: Inhibition of carcinogenesis by dietary polyphenolic compounds. Annu Rev Nutr 21: 381-406, 2001. PMID: 11375442, DOI: 10.1146/annurev.nutr.21.1.381.

53 Jeon D, Jeong MC, Jacob B, Bang JK, Kim EH, Cheong C, Jung ID, Park Y and Kim Y: Investigation of cationicity and structure of pseudin-2 analogues for enhanced bacterial selectivity and anti-inflammatory activity. Sci Rep 7: 1455, 2017. PMID: 28469145, DOI: 10.1038/s41598-017-01474-0.

54 Stangl V, Lorenz M, Ludwig A, Grimbo N, Guether C, Sanad W, Ziemer S, Martus P, Baumann G and Stangl K: The flavonoid phloretin suppresses stimulated expression of endothelial adhesion molecules and reduces activation of human platelets. $\mathrm{J}$ Nutr 135: 172-178, 2005. PMID: 15671209, DOI: 10.1093/jn/ 135.2.172.
55 Lee EJ, Kim JL, Gong JH, Park SH and Kang YH: Inhibition of osteoclast activation by phloretin through disturbing $\alpha v \beta 3$ integrin-c-Src pathway. Biomed Res Int 2015: 680145, 2015. PMID: 25834823, DOI: 10.1155/2015/680145.

56 Zhang HZ, Kasibhatla S, Wang Y, Herich J, Guastella J, Tseng B, Drewe J and Cai SX: Discovery, characterization and SAR of gambogic acid as a potent apoptosis inducer by a HTS assay. Bioorg Med Chem 12: 309-317, 2004. PMID: 14723951, DOI: 10.1016/j.bmc.2003.11.013.

57 Zhao L, Guo QL, You QD, Wu ZQ and Gu HY: Gambogic acid induces apoptosis and regulates expressions of Bax and $\mathrm{Bcl}-2$ protein in human gastric carcinoma MGC-803 cells. Biol Pharm Bull 27: 998-1003, 2004. PMID: 15256729, DOI: 10.1248/ bpb.27.998.

58 Wu ZQ, Guo QL, You QD, Zhao L and Gu HY: Gambogic acid inhibits proliferation of human lung carcinoma SPC-A1 cells in vivo and in vitro and represses telomerase activity and telomerase reverse transcriptase mRNA expression in the cells. Biol Pharm Bull 27: 1769-1774, 2004. PMID: 15516720, DOI: 10.1248/bpb.27.1769.

59 Pandey MK, Sung B, Ahn KS, Kunnumakkara AB, Chaturvedi $\mathrm{MM}$ and Aggarwal BB: Gambogic acid, a novel ligand for transferrin receptor, potentiates TNF-induced apoptosis through modulation of the nuclear factor-kappaB signaling pathway. Blood 110: 3517-3525, 2007. PMID: 17673602, DOI: 10.1182/blood-2007-03-079616.

60 Yi T, Yi Z, Cho SG, Luo J, Pandey MK, Aggarwal BB and Liu M: Gambogic acid inhibits angiogenesis and prostate tumor growth by suppressing vascular endothelial growth factor receptor 2 signaling. Cancer Res 68: 1843-1850, 2008. PMID: 18339865, DOI: 10.1158/0008-5472.CAN-07-5944.

Received January 7, 2019

Revised January 21, 2019

Accepted January 22, 2019 